\title{
DIFERENTES AMBIENTES PARA AVALIAÇÃO DA SENSIBILIADE AO ÁCIDO GIBERÉLICO EM GENÓTIPOS DE TRIGO (Tritícum aesíivum L.)
}

\author{
DIFFERENT ENVIRONMENT FOR THE EVALUATION OF GIBERELLIC ACID \\ SENSITIVITY IN WHEAT (Triticum aestivum L.) GENOTYPES
}

\section{Paulo César Canci ${ }^{1}$ Fernando Irajá Felix de Carvalho ${ }^{2}$ José Fernandes Barbosa Neto $^{2}$ Marco António Rott de Oliveira ${ }^{3}$ Francisco de Assis Franco $^{3}$}

RESUMO

O presente trabalho foi conduzido com o objetivo de analisar diferentes ambientes para a identificação de genótípos portadores de genes redutores da estatura de planta em trigo, através da reação de sensibilidade ao ácido giberélico (AG). $O$ experimento foi instalado no ano de 1995 em casa de vegetação (CV) e laboratório (LA) na Faculdade de Agronomia da Universidade Federal do Rio Grande do Sul - FA/UFRGS, Porto Alegre e a campo (CA), em Eldorado do Sul, RS. Foram avaliados 6 genótípos de diferentes estaturas de planta em $O$ e IDOppm de AG em CV e LA e O, 100 e lOOOppm de AG aplicados quando as plantas apresentavam duas e quatro folhas em CA. A determinação da estatura foi realizada aos 20 dias após a aplicação do tratamento em $C V, 18$ dias em LA e em quatro avaliações semanais em CA. A separação dos genótípos de acordo com a sensibilidade ao $A G$ foi possível nos três ambientes, sem que a ordem de resposta fosse alterada. A diferença de estatura entre os tratamentos foi utilizada para a comparação entre ambientes e as maiores diferenças de estatura foram observadas em $\mathrm{CV}$ e CA. A interação genótipo $x$ ambiente não foi significativa revelando a possibilidade de realização do teste em campo. Para todos os tratamentos aplicados foi possível identificar os genótípos sensíveis ao AG a partir dos 7 dias, através da determinação da estatura e peta identificação visual das plantas.

Palavras-chave: Tritícum aestivum, sensibilidade ao ácido giberélico, estatura, Rht, e Rht;
SUMMARY

This experiment was conducted to analyse different environments in lhe indentification of dv/arf genes $m$ wheat througth the giberellic acid (GA) sensitivity reaction. The tests were conducted in 1995, in a greenhouse (GH), laboratory (LA) andfield (Ff) in Porto Alegre and Eldorado do Sul, RS, Brazil. Six genotypes with different heigth were evatualed in GH and LA by treatments with $O$ and $100 \mathrm{GA}$ ppm, and in lhe Fl, when plants had two tofour leaves in lhe treatments with O, 100 and $1000 \mathrm{GA}$ ppm. The heigth measurement was done 20 days after lhe aplication of GA in GH, 18 days in LA andfour-week evaluations in lhe Fl. The identijication of GA sensitive genotypes was possible in ali environments. The heigth dijference between the treatments was used to compare the environments, and the targer difference were observed in $G H$ and in the Fl. The genotype $x$ environment interaction was not significam, demonstrating showing the possibility ofusing this identification test in thefield. Seven days after the tratment aplication the sensitive ofGA genotypes could be detected througth height measurements and visual evaluation.

Key words: Triticum aestivum, giberelic acid, sensitivity, dwarf genes, Rhti, Rht.

\footnotetext{
${ }^{1}$ Engenheiro Agrônomo, Estudante do curso de Pós-Graduação em Agronomia da Universidade Federal do Rio Grande do Sul (UFRGS), Bolsista do CNPq.

${ }^{2}$ Professor, Faculdade de Agronomia, UFRGS, Caixa Postal 776, 90001-970, Porto Alegre - rs, Pesquisador do CNPq. Autores para correspondência.

${ }^{3}$ Engenheiro Agrônomo, MSc., COODETEC, PR.
} 


\section{INTRODUÇÃO}

A manipulação de genes para o caráter estatura de planta tem sido de grande utilidade para a obtenção de genótipos resistentes ao acamamento e de alto rendimento de grãos. No melhoramento de trigo a redução da estatura pode ser obtida com a utilização de genes de grande efeito sobre o caráter ou com o acúmulo de genes de pequeno efeito. Vários genes para porte baixo em trigo foram descritos, entretanto, os genes Rht, e Rht; provenientes da variedade japonesa Norin 10 tem sido os de maior importância (GALE et al., 1981; GALE \& YOUSSEFIAN, 1985) e de ampla utilização nos programas de melhoramento. Contudo, o conhecimento da atual constituição genética responsável pela redução da estatura de planta em trigo tem revelado um pequeno incremento da variabilidade do caráter, reduzindo o número de classes genotípicas dificultando a seleção de genótipos superiores.

Em trigo, a resposta diferencial a aplicação exógena de ácido giberélico entre genótipos de portealto e baixo tem sido observada. Nos genótipos de porte baixo os genes de redução da estatura de planta são insensíveis ao ácido giberélico e os genótipos de porte alto são sensíveis o que permite diferenciar genótipos de diferentes estaturas (ALLAN et al., 1959; GALE \& GREGORY, 1977; GALE \& LAW, 1977). Avaliações genéticas e fisiológicas realizadas, indicaram que os dois fenótipos são diferentes mas resultam da mesma ação pleiotrópica de um mesmo loco (GALE \& MARSHALL, 1976; GALE \& GREGORY, 1977) de forma a ser possível a separação de efeitos de estatura através da insensibilidade ao ácido giberélico.

A identificação de plantas de trigo portadoras dos genes de nanismo, é possível de ser realizada em laboratório ou em casa de vegetação pela aplicação exógena de ácido giberélico. Inúmeros trabalhos com este objetivo tem sido realizados utilizando doses de ácido entre 10 a 1OOppm (ALLAN $\boldsymbol{e t}$ al., 1959; FEDERIZZI $\boldsymbol{e}$ t al., 1988; FEDERIZZI $\boldsymbol{e}$ t al., 1992, DORNELLES $\boldsymbol{e}$ t al., 1995), tendo sido a dose de 100 ppm a que melhor proporcionou a separação das classes fenotípicas (FEDERIZZI et al:; 1988; DORNELLES et al., 1995). Os critérios mais utilizados para avaliação da sensibilidade dos genótipos ao ácido giberélico têm sido o tamanho de planta, inserção da primeira e segunda folha, diferença entre a inserção da primeira e segunda folha e o comprimento da segunda folha. Também, segundo GREGORY (1984), a seleção visual pode ser utilizada no estádio de plântula em gerações iniciais e avançadas.
A seleção em ambiente controlado, como casa de vegetação e laboratório, tem sido utilizada para a identificação de genótipos de porte baixo. Entretanto, o espaço físico tem limitado a utilização desta técnica, principalmente em populações segregantes com um grande número de plantas e gerações por cruzamento. Desta forma, o estudo da resposta dos genótipos ao ácido giberélico em diferentes ambientes que possibilitem a realização da técnica de forma simples e em uma escala maior, é de extrema importância para a identificação de genótipos portadores de genes redutores da estatura de planta nos programas de melhoramento de trigo.

Este trabalho teve por objetivo: (l) estudar a utilização de diferentes ambientes para a identificação de genótipos portadores de genes redutores da estatura de planta em trigo através da reação de sensibilidade ao ácido giberélico e (2) testar diferentes épocas de aplicação e doses do produto para adequar a técnica em campo.

\section{MATERIAIS E MÉTODOS}

Os experimentos com trigo foram conduzidos em casa de vegetação e laboratório da Faculdade de Agronomia da UFRGS e em campo na estação experimental localizada em Eldorado do Sul, RS.

Ambiente 1 (Casa de Vegetação). O experimento foi conduzido em condições semicontroladas em casa de vegetação nos meses de junho e julho de 1995. Foram utilizados dois genótipos de porte alto (CEP 24 e IAC 5), três de porte intermediário (OC 9510, Desconhecido e PF 83348) e um de porte baixo (IPF 55245). Os níveis de ácido giberélico (AG) aplicados foram $\mathrm{O}$ e 100ppm em adição a uma solução nutritiva utilizada por DORNELLES et al. (1995) com pH ajustado para 7. A unidade experimental foi composta por cinco sementes de cada genótipo, semeada a profundidade de $2 \mathrm{~cm}$ em copos plásticos medindo $13 \mathrm{~cm}$ de altura por $10 \mathrm{~cm}$ de diâmetro contendo vermiculita como substrato. As unidades experimentais foram colocadas em bandejas plásticas as quais receberam os tratamentos solução nutritiva e solução nutritiva + 100 ppm de ácido giberélico. O delineamento experimental utilizado foi o completamente casualisado com três repetições. As sementes foram pré- germinadas em laboratório e a semeadura foi efetuado no dia 19/06/95. Os tratamentos foram aplicados no dia da semeadura e em intervalos de três dias, o que foi suficiente para manter a umidade nos vasos até a coleta dos dados. A temperatura média mínima e máxima registradas na casa de vegetação neste período foram de $8^{\circ}$ e $35{ }^{\circ} \mathrm{C}$, respectivamente. A 
avaliação dos dados foi realizada 20 dias após a emergência, sendo determinada a estatura de planta tomando a medida da coroa a extremidade da folha de maior crescimento sobre o afilho principal.

Ambiente 2 (Laboratório). O experimento foi conduzido no Laboratório de Cultura de Tecidos e Citogenética nos meses de maio e junho de 1995. O método utilizado foi o descrito por CAMARGO \& OLIVEIRA (1981) e adaptado por DORNELLES et al. (1995) para possibilitar a avaliação da sensibilidade ao ácido giberélico. Os tratamentos solução nutritiva e solução nutritiva $+100 \mathrm{ppm}$ de ácido giberélico foram utilizados no ensaio. As sementes foram submetidas a desinfestação em hipoclorito de sódio a $50 \%$ por um minuto seguida por lavagem em água destilada. Posteriormente, foram pré-germinadas em placas de Petri e semeadas sobre tela plástica acoplada a tampa de um vaso com solução tratamento (8,5 litros), dispostos em um tanque metálico (banho maria) com temperatura mantida em $25{ }^{\circ} \mathrm{C}$. Nos vasos um sistema de aeração forneceu oxigénio as plantas que permaneceram sob luz constante. As plantas permaneceram em crescimento durante 18 dias, quando foi efetuada a determinação da estatura de planta. O delineamento experimental utilizado foi o inteiramente casualizado com três repetições, sendo a unidade experimental constituída por 10 plantas.

Ambiente 3 (Campo). $\mathrm{O}$ ensaio foi conduzido em campo nos meses de agosto e setembro de 1995. O delineamento experimental utilizado foi o de blocos ao acaso com três repetições. Os tratamentos foram $\mathrm{O}, 100$ e 1000ppm de AG aplicados quando as plantas apresentavam segunda a terceira folha (2 F 100 e 2 F 1000 respectivamente) e quarta para quinta folha (4 F 100 e 4 F 1000). As plantas foram pulverizadas até o molhamento completo. A unidade experimental foi composta de uma linha de $2 \mathrm{~m}$ de comprimento espaçada de $0,3 \mathrm{~m}$ com 10 sementes por linha. As medidas de estatura das plantas, tomadas no afilho principal, foram efetuadas semanalmente até os 28 dias após a aplicação do tratamento. Durante o desenvolvimento do ensaio foi realizada a observação visual da reação de sensibilidade ao ácido giberélico dos genótipos. Os dados da avaliação aos 15 dias do tratamento $(2 \mathrm{~F}$ 100) foram utilizados para as comparações entre os diferentes locais.

Os dados dos três experimentos foram submetidos a análise de variância (teste de F) e as médias comparadas pelo teste de Tukey a 0,05 (STEEL \& TORRIE, 1980). O parâmetro diferença de estatura de planta obtido da diferença de estatura de planta entre os tratamentos $\mathrm{O}$ e 100 ppm de AG foi utilizado neste estudo para a comparação entre locais.

\section{RESULTADOS E DISCUSSÃO}

Para o carácter estatura de planta os efeitos de ambiente, genótipo e tratamento, bem como as interações genótipo $\mathrm{x}$ ambiente e genótipo $\mathrm{x}$ tratamento foram significativas. Estes resultados indicam a reação diferencial dos genótipos de diferentes estaturas à aplicação do ácido giberélico e aos diferentes ambientes. Quando os genótipos de diferente estatura foram submetidos a ação do tratamento (Tabela 1) houve a separação dos genótipos de acordo com a sensibilidade ao AG. Os genótipos de porte alto foram

Tabela 1 - Médias da estrutura de planta $(\mathrm{cm})$ e diferença de estatura - DIF $(\mathrm{cm})$ de genótipos de trigo submetidos as doses de 0 a 100 ppm de ácido gibérelico em três ambientes.

\begin{tabular}{|c|c|c|c|c|c|c|c|c|}
\hline \multirow{2}{*}{ Genótipo } & \multirow{2}{*}{$\begin{array}{l}\text { Estatura } \\
(\mathrm{cm})\end{array}$} & \multicolumn{2}{|c|}{ Casa de vegetação } & \multicolumn{2}{|c|}{ Laboratório } & \multicolumn{2}{|c|}{ Campo } & \multirow{2}{*}{$\operatorname{DIF}(\mathrm{cm})$} \\
\hline & & 0 & 100 & 0 & 100 & 0 & 100 & \\
\hline CEP 24 & 110,2 & $B * 29,95 b$ & $\mathrm{~A} 48,85 \mathrm{a}$ & A $39,03 \mathrm{~b}$ & A 52,03 a & B $33,67 \mathrm{~b}$ & A $49,55 a$ & A 18,53 \\
\hline IAC 5 & 120,2 & $\mathrm{~A} 36,07 \mathrm{~b}$ & $\mathrm{~A} 48,30 \mathrm{a}$ & A $37,45 \mathrm{~b}$ & A 50,02 a & A $40,71 \mathrm{~b}$ & A $53,18 \mathrm{a}$ & A 14,76 \\
\hline OC 9510 & 91,1 & BC $2629 b$ & $\mathrm{~B} 40,58 \mathrm{a}$ & B 33,73 a & B 37,83 a & C $26,06 \mathrm{~b}$ & В $38,88 \mathrm{a}$ & B 08,87 \\
\hline PF 83348 & 100,7 & $\mathrm{BC} 2722 \mathrm{~b}$ & $\mathrm{C} 35,29 \mathrm{a}$ & C 28,86 a & $\mathrm{C} 28,24 \mathrm{a}$ & $\mathrm{C} 28,60 \mathrm{~b}$ & $\mathrm{CD} 33,98 \mathrm{a}$ & BC 4,99 \\
\hline Desconhecido & 92,5 & BC2818b & $\mathrm{C} 36,27 \mathrm{a}$ & $\mathrm{C} 25,58 \mathrm{~b}$ & C 29,21 a & C 27,64 a & C $30,23 a$ & CD 3,63 \\
\hline IPF 552456 & 61,2 & $\mathrm{C} 23,15 \mathrm{a}$ & $\mathrm{D} 21,77 \mathrm{a}$ & D 18,17 a & D 17,62 a & $\mathrm{C} 28,81 \mathrm{a}$ & D $26,97 a$ & D $-0,53$ \\
\hline Média do tratamento & & $28,47 b$ & $38,51 \mathrm{a}$ & $30,14 \mathrm{~b}$ & 35,82 a & 30,91 a & $38,79 \mathrm{~b}$ & \\
\hline Média DIF & & & $9,45 \mathrm{a}$ & & $5,82 \mathrm{~b}$ & & $10,37 \mathrm{a}$ & \\
\hline
\end{tabular}

*Tratamento com médias não seguidas de mesma letra, maiúsculo na coluna e minúscula na linha diferem estatisticamente pelo teste de Tukey a $5 \%$ de probabilidade. 
os mais sensíveis, os de porte baixo insensíveis e os genótipos de porte intermediário apresentaram uma reação intermediária..

A resposta diferenciada dos genótipos de trigo a aplicação exógena de 100ppm de AG confirmam os dados obtidos em trabalhos anteriores (ALLAN $\boldsymbol{e}$ t al., 1959; GALE \& GREGORY, 1977; GALE \& YOUSSEFIAN, 1985; FEDERIZZI $\boldsymbol{e}$ t al., 1988; DOKNELLES et al., 1995) com este cereal. Este comportamento foi semelhante nos diferentes ambientes, não alterando a ordem dos genótipos quanto a sensibilidade ao AG.

A diferença de estatura, obtida com a aplicação dos tratamentos, foi utilizada por ser uma variável independente do efeito ambiental no crescimento das plantas, possibilitando a comparação entre locais com conduções experimentais diferenciadas. Quando utilizada a diferença de estatura os efeitos de ambiente e genótipo foram significativos. A interação genótipo $\mathrm{x}$ ambiente não foi significativa indicando que os genótipos quando submetidos ao AG apresentam o mesmo comportamento independente do local onde foi realizado o ensaio. Isto explica que a interação genótipo $\mathrm{x}$.ambiente observada na análise envolvendo os diferentes tratamentos para estatura de planta, foi devida ao crescimento diferencial dos genótipos nos ambientes e não devida a resposta de crescimento proporcionada pelo AG.

As maiores diferenças entre os tratamentos para a característica estatura de planta foram obtidos em casa de vegetação e campo (Tabela 1), onde as condições de luz e temperatura mais adequadas podem ter propiciado o maior crescimento diferencial nestes ambientes. $\mathrm{Na}$ análise dos genótipos para a diferença de estatura de planta, houve a separação dos genótipos em classes, de acordo com a sensibilidade e tamanho de planta. Os genótipos de porte alto (CEP 24 e IAC 5) foram os que apresentaram maiores diferenças de estatura. Estes resultados indicam que a aplicação exógena de ácido giberélico em campo pode ser realizada para a identificação da sensibilidade dos genótipos através da avaliação da estatura de planta. As maiores médias da diferença de estatura observadas em casa de vegetação e a campo, também indicam um grau de confíabilidade maior para a realização da técnica, quando comparado às obtidas em laboratório.

$\mathrm{Na}$ análise da variância para estatura de planta em campo os efeitos de genótipo, tratamento, época de avaliação e todas as interações foram significativos. Analisando o comportamento dos genótipos de porte alto (Figura Ia), intermediário (Figura 1 b) e baixo (Figura 1 c) nos diversos tratamentos, observamos que, a partir dos 7 dias após a aplicação do tratamento, é possível identificar com segurança os genótipos sensíveis para todos os tratamentos a base de AG, quando comparados com a padrão. O genótipo de porte baixo se mostrou insensível, não respondendo a aplicação dos tratamentos, o que era esperado, devido a sua constituição genética para porte de planta e sensibilidade ao AG. A dose de 1000 ppm foi mais eficiente em cada época de aplicação, entretanto, a dose de 100 ppm pode ser utilizada com eficiência e economia. Os estádios de 2 a 3 folhas e de 4 a 5 folhas podem ser utilizados para a aplicação de AG, porém, a avaliação realizada na primeira época permite uma maior rapidez na obtenção dos resultados, o que é desejado quando se avalia grande quantidade de material.

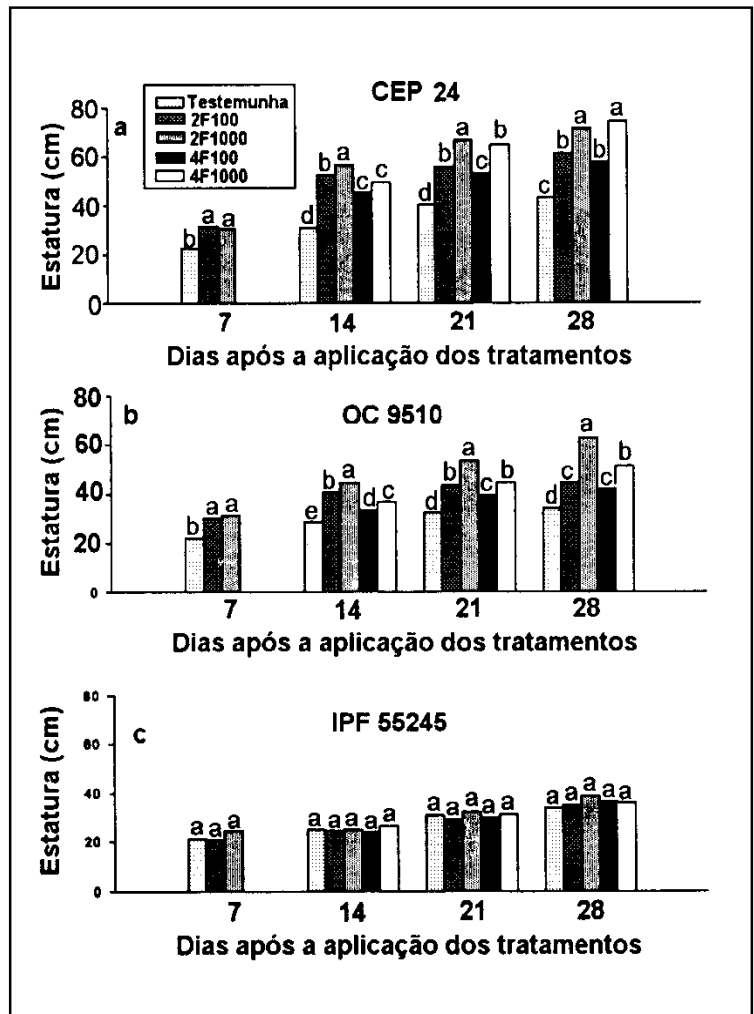

Figura 1 - Comportamento dos genótipos de porte alto (a), intermediário (b) e baixo (c) para estrutura submetidos a duas épocasde aplicação (duas e quatro folhas) e duas doses (100 e 1000ppm) de ácido giberélico em quatro épocas de avaliação.

A identificação visual das plantas também foi possível na primeira semana após a aplicação do tratamento, pela elongação do entrenó nos genótipos sensíveis, como indicado por GREGORY (1984), pela 
avaliação efetuada no estádio de plântula. As plantas sensíveis ao AG apresentaram clorose e estiolamento nos primeiros dias após o tratamento.

\section{CONCLUSÕES}

A identificação da sensibilidade ao ácido giberélico(AG) em genótipos de trigo é possível de ser efetuada em condições de campo; a identificação de plantas sensíveis ao AG em campo e casa de vegetação utilizando como parâmetro a estatura de planta é de maior confiabilidade do que a realizada em condições de laboratório; a dose de 100ppm de AG e a aplicação no estádio de duas a três folhas podem ser utilizadas para identificar genótipos sensíveis nas condições de campo a partir dos 7 dias após a aplicação do AG; a avaliação visual pode ser utilizada como meio eficiente para identificar a sensibilidade dos genótipos ao (AG) em campo.

\section{REFERÊNCIAS BIBLIOGRÁFICAS}

ALLAN, R.E., VOGEL, O.A., CRADDOCK, J.C. Comparative response to giberelic acid of dwarf, semidwarf, and standart short and tall winter wheat varieties. Agron J Madison, v. 51, p.737-740, 1959

CAMARGO, C. E., OLIVEIRA, O.F. de. Tolerância de cultivares de trigo a diferentes níveis de alumínio em solução nutritiva e no solo. Bragantia, Campinas, v. 40, p. 21-31, 1981.

DORNELLES, A.L.C., CARVALHO, F.I.F., FEDERIZZI, L.C., et al. O uso de ácido giberélico em solução nutritiva na avaliação precoce de estatura de genótipos de trigo hexaplóide. Ciência
Rural, Santa Maria, v. 25, n. 3, p. 363-366, 1995.

FEDERIZZI, L.C., CARVALHO, F.I.F. de, OLIVEIRA, M.A.R., et al. Avaliação da resposta de genótipos de trigo (Triticum aestívum L.) de diferentes estaturas à aplicação de ácido giberélico no estádio de plântula. Rev Centro de Ciências Rurais, Santa Maria, v. 18, n. 2, p. 149-161, 1988

FEDERIZZI, L.C.; CARVALHO, F.I.F. de; OLIVEIRA, M. A. R. de. Genética da insensibilidade ao ácido giberélico em genótipos de trigo com diferentes estaturas. Pesq Agropec Brás, Brasília, v. 27, n. 8, p. 1183-1193, 1992.

GALE, M.D., GREGORY, R.S. A rapid method for early generation selection of dwarf genotypes in wheat. Euphytica, Wageningen, v. 26, p. 733-738, 1977.

GALE, M.D., LAW, C.N. Norin 10 - based semi- dwarfism. In: MUHAMMED, A., AKSEL, R.. BIRSTEL, R.C. Genetic diversity in plants. New York: Plenun, 1977. p. 132 - 152.

GALE, M.D., MARSHALL, G.A. The ehromossomal location Gai 1 and Rht 1 , genes for gibbereilin insensitivity and semidwarfism, in a derivative of Norin 10 wheat. Heredity, London,v.37,n.2,p.283 - 289, 1976.

GALE , M.D., MARSHALL, G.A.; RAO, M.V. A classification of the Norin 10 and Tom Thumb dwarfing genes in british, mexican, indian and other hexaploid bread wheat varieties. Euphytica, Wageningen, v. 30, p. 355 -361, 1981.

GALE, M.D., YOUSSEFIAN, S. Dwarfing genes in wheat. IN: RUSSEL, G.E. (ed): Progress in plant breeding. London: Butterworthsp, 1985. p. 1-35.

GREGORY, R.S. A technique for identufying major dwarfing genes in triticale. Z Pflanzenzüchtg, Berlin, v. 92, p. 177$184,1984$.

STEEL, R.G.D., TORRIE, J.H. Principies and procedures of statistics. New York: McGraw, 1980.630 p.

Ciência Rural, v. 27, n. 1, 1997. 